\title{
A COMPARISON BETWEEN PLOT AND POINT SAMPLING USING A COMPUTER BASED TREE POPULATION OF PinUs caribaea SRI LANKA
}

\author{
W M Lalith Perera and S G Banyard \\ Department of Forestry and Environmental Science \\ University of Sri Jayewardenepura, Nugegoda.
}

Research was conducted in the University Forest at Yagirala Forest Reserve, Kalutara District, Sri Lanka, to compare the efficiency of point and plot sampling in Pinus caribaea plantation using computer simulated sampling on a population of trees using data collected in the field. In all, 3294 trees on $\mathbf{5 . 4}$ hectares constitute the population. The data base has been filed with tree number, dbh, $\mathrm{X}$ and $\mathrm{Y}$ co-ordinates. Edge effect bias was minimized using the reflection method.

Random sampling was used in all cases for sample sizes $n=10,20,30,60$ and 100 . In order to make meaningful comparisons, the concept of equivalent plot was used which aimed at obtaining equal tallies per sampling unit for point and plot sampling. Basal area factors applied were 2, 4, 9 and 16. Efficiency for given point - plot equivalents were based on standard error \% and cost values (where cost was based on time). In 19 of the 20 point-plot combinations studied, point sampling was found to be the more efficient. The most suitable BAF is BAF2 and it is recommended that point sampling be applied in plantation forest inventories in Sri Lanka where trained staff are available.

Proceedings of the Third Annual Forestry Symposium 1997, of the Department of Forestry and Environmental Science, University of Sri Jayewardenepura, Sri Lanka 